\title{
Analysis of Nausea in Clinical Studies of Lubiprostone for the Treatment of Constipation Disorders
}

\author{
Byron Cryer $^{1} \cdot$ Douglas A. Drossman ${ }^{2} \cdot$ William D. Chey ${ }^{3} \cdot$ Lynn Webster $^{4}$. \\ Sepideh Habibi ${ }^{5}$ Martin Wang ${ }^{6}$
}

Received: 22 September 2016/Accepted: 11 July 2017/Published online: 28 August 2017

(c) The Author(s) 2017. This article is an open access publication

\begin{abstract}
Background Lubiprostone is a $\mathrm{ClC}-2$ chloride channel activator approved for the treatment of chronic idiopathic constipation (CIC) and opioid-induced constipation (OIC) in adults and irritable bowel syndrome with constipation (IBS-C) in women. Lubiprostone is generally well tolerated, with nausea being the most common adverse event. Aims To characterize nausea with lubiprostone using pooled results from clinical studies in patients with CIC, OIC, or IBS-C.

Methods Data from three 3- and 4-week placebo-controlled studies and three long-term open-label studies were pooled for the CIC analysis. The OIC and IBS-C analyses each used pooled data from three 12-week placebo-
\end{abstract}

Electronic supplementary material The online version of this article (doi:10.1007/s10620-017-4680-1) contains supplementary material, which is available to authorized users.

\author{
Byron Cryer \\ Byron.cryer@UTSouthwestern.edu \\ Douglas A. Drossman \\ douglas_drossman@med.unc.edu \\ William D. Chey \\ wchey@med.umich.edu \\ Lynn Webster \\ lrwebstermd@gmail.com \\ Sepideh Habibi \\ shabibi@sucampo.com \\ Martin Wang \\ mwang@sucampo.com \\ 1 Internal Medicine, Veterans Affairs North Texas Health Care \\ System, University of Texas Southwestern Medical School, \\ 5323 Harry Hines Blvd, Dallas, TX 75390, USA
}

controlled studies and one 36-week open-label extension study.

Results The populations included the following numbers of patients: CIC, 316 (placebo) and 1113 (lubiprostone 24 mcg twice daily [BID]); OIC, 652 (placebo) and 889 (lubiprostone $24 \mathrm{mcg}$ BID); and IBS-C, 435 (placebo) and 1011 (lubiprostone $8 \mathrm{mcg}$ BID). The incidence of nausea in lubiprostone-treated patients ranged from 11.4 to $31.1 \%$, with the highest incidence in patients with CIC. Among patients with any nausea, most reported only mild or moderate severity (96.5-99.1\% across indications) and only one event (83.6-88.7\%); most events occurred within the first 5 days of treatment.

Conclusions Nausea was the most common adverse event following the treatment with lubiprostone. Event rates varied by indication and dose, and the majority of nausea adverse events were mild to moderate in severity. Nausea events predominantly occurred early in the treatment period in all of the pooled study populations.

2 UNC Center for Functional GI and Motility Disorders, University of North Carolina at Chapel Hill, 55 Vilcom Center Drive, Suite 110, Chapel Hill, NC 27514, USA

3 Internal Medicine, University of Michigan School of Medicine, 3912 Taubman Center SPC 5362, Ann Arbor, MI 48109, USA

4 PRA Health Sciences, 3838 S 700 E Suite 202, Salt Lake City, UT 84106, USA

5 Drug Safety, Sucampo Pharma Americas, LLC, 4520 EastWest Highway, Bethesda, MD 20814, USA

6 Biostatistics, Sucampo Pharma Americas, LLC, 4520 EastWest Highway, Bethesda, MD 20814, USA 
Keywords Lubiprostone $\cdot$ Nausea $\cdot$ Irritable bowel syndrome with constipation - Opioid-induced constipation . Chronic idiopathic constipation

\section{Introduction}

Lubiprostone is an orally active $\mathrm{ClC}-2$ chloride channel activator indicated for the treatment of chronic idiopathic constipation (CIC) in adults (24 mcg twice daily [BID]), opioid-induced constipation (OIC) in adults with chronic non-cancer pain (24 mcg BID), and irritable bowel syndrome with constipation (IBS-C) in women $\geq 18$ years old (8 mcg BID) [1, 2]. Structurally, lubiprostone is a prostone; mechanistically, it acts locally within the gastrointestinal tract to promote intestinal secretion by activating $\mathrm{ClC}-2$ chloride channels, resulting in the addition of fluid to stool and more rapid transit time [2]. In healthy adults, lubiprostone slows gastric emptying and decreases small bowel transit time [3]. The overall safety profile of lubiprostone is consistent among clinical studies; lubiprostone is generally well tolerated, with most adverse events (AEs) reported as mild or moderate in severity [4-6]. Nausea was generally the most frequently reported AE in individual studies of patients receiving lubiprostone [5-16]. The clinical profiles of patients who are more likely to experience nausea with lubiprostone and the characteristics of lubiprostone-related nausea have not been well delineated.

The purpose of this article is to analyze the incidences of nausea in pivotal and long-term open-label safety studies of lubiprostone in patients with CIC, OIC, and IBS-C. This comprehensive characterization of nausea may serve to identify patients who are at greater risk of experiencing nausea after treatment with lubiprostone, inform clinicians about the expected timing and severity of nausea when it does occur, and provide data on the likelihood that treatment may continue following reduction or temporary interruption of dosing.

\section{Methods}

\section{Included Studies}

In these post hoc analyses, data from the clinical development program for each indication (Table 1; Figure S1) were combined. Only data for patients assigned to receive placebo or the currently approved doses of lubiprostone were included in the present analyses (Figure S1). All randomized controlled trials (RCTs) analyzed in these post hoc analyses fulfilled criteria on the Jadad scale assessing the quality of studies [17]. For CIC treatment, data were from six studies. Three of the CIC studies were randomized, double-blind, placebo-controlled trials lasting 3-4 weeks $[5,7,8]$, and two were open-label 24- and 48-week extension studies [9, 10]. The sixth CIC study included 4 weeks of active treatment, a 3-week randomized withdrawal, and a 48-week open-label period [6]. Lubiprostone was administered at $24 \mathrm{mcg}$ BID in all of the studies except the 3-week study, in which patients were treated with 24,48 , or $72 \mathrm{mcg}$ (total dose). For OIC treatment, data were from three randomized, double-blind, 12-week, placebo-controlled studies (registered on ClinicalTrials.gov as NCT01298219 [11], NCT00595946, and NCT00597428) and one 36-week open-label extension study (NCT00620061) [16]. In all of these OIC studies, patients were treated with $24 \mathrm{mcg}$ BID lubiprostone. For IBS-C treatment, data were from three randomized, double-blind, 12-week, placebo-controlled studies (NCT00380250 and NCT00399542 [13], and a third study [14]) and one 36-week open-label extension study (continuation of NCT00380250 and NCT00399542) [15]. In one of the IBS-C studies [14], patients were treated orally with 8,16 , or 24 mcg BID lubiprostone; the treatment dose was $8 \mathrm{mcg}$ BID in all of the other studies. In all of the studies, patients were instructed to take their medications with the morning and evening meals.

\section{Patient Criteria}

Patient criteria specific to the clinical studies have been described previously [5-16]. In all of the lubiprostone development programs (CIC, OIC, and IBS-C), patients were required to be $\geq 18$ years of age and to meet criteria with respect to the maximum weekly frequency of spontaneous bowel movements (SBMs) and symptoms of constipation. "Spontaneous" was defined as a bowel movement occurring without the use of laxatives or stool softeners within the prior 24-h period. Signs and symptoms of constipation comprised $\geq 1$ of the following, which had to be present for $\geq 25 \%$ of the SBMs during each week of the baseline washout period: hard or very hard stools, sensation of incomplete evacuation (for CIC and OIC studies), and/or moderate to very severe straining associated with the SBMs. Exclusion criteria included documented mechanical obstruction; organic bowel disorders; constipation secondary to a documented cause; clinically significant cardiovascular, liver, lung, neurologic, or psychiatric disorder; or significant laboratory abnormalities.

Patients in the CIC studies had a documented history of constipation and, during the baseline washout period, $<3$ SBMs per week and signs and symptoms of constipation. Patients in the OIC studies had chronic non-cancer-related pain being treated consistently with an opioid for $\geq 30$ days before the baseline washout and that would require 
Table 1 Study design summary

\begin{tabular}{|c|c|c|c|c|}
\hline Study & Design & Treatment $(n=)^{*}$ & $\begin{array}{l}\text { Duration of treatment } \\
\text { (week) }\end{array}$ & Dosing instructions \\
\hline \multicolumn{5}{|l|}{ CIC } \\
\hline RTU0211SC9921 & $\begin{array}{l}\text { Double-blind } \\
\text { Randomized }\end{array}$ & $\begin{array}{l}\text { Placebo (33) } \\
\text { LUB } 24 \mathrm{mcg}(29) \\
\text { LUB } 48 \mathrm{mcg}(32) \\
\text { LUB } 72 \mathrm{mcg}(33)\end{array}$ & 3 & $\begin{array}{l}\text { Before meals, w } / \geq 8 \text { oz of } \\
\text { water }\end{array}$ \\
\hline RTU0211SC0131 & $\begin{array}{l}\text { Double-blind } \\
\text { Randomized }\end{array}$ & $\begin{array}{l}\text { Placebo (122) } \\
\text { LUB } 24 \text { mcg BID (120) }\end{array}$ & 4 & w/food and $\geq 8$ oz of water \\
\hline SPI0211SC0232 & $\begin{array}{l}\text { Double-blind } \\
\text { Randomized }\end{array}$ & $\begin{array}{l}\text { Placebo (118) } \\
\text { LUB } 24 \text { mcg BID (119) }\end{array}$ & 4 & w/food and $\geq 8$ oz of water \\
\hline RTU0211SC01S1 & Open-label & LUB 24 mcg BID (306) & 24 & w/food and $\geq 8$ oz of water \\
\hline $\begin{array}{l}\text { RTU0211SC01S2 } \\
\quad(\text { period 1) }\end{array}$ & $\begin{array}{l}\text { Active treatment } \\
\text { Randomized } \\
\text { withdrawal }\end{array}$ & $\begin{array}{l}\text { LUB } 24 \text { mcg BID (128) } \\
\text { Placebo (42) } \\
\text { LUB } 24 \text { mcg BID (45) }\end{array}$ & $\begin{array}{l}4 \\
3\end{array}$ & w/food and $\geq 8$ oz of water \\
\hline $\begin{array}{l}\text { RTU0211SC01S2 } \\
\text { (period 2) }\end{array}$ & Open-label & LUB 24 mcg BID (248) & 48 & w/food and $\geq 8$ oz of water \\
\hline $\begin{array}{l}\text { SPI0211SC02S3 } \\
\text { OIC }\end{array}$ & Open-label & LUB 24 mcg BID (324) & 48 & w/food and $\geq 8$ oz of water \\
\hline OBD-1033 & $\begin{array}{l}\text { Double-blind } \\
\text { Randomized }\end{array}$ & $\begin{array}{l}\text { Placebo ( } 220) \\
\text { LUB } 24 \text { mcg BID (219) }\end{array}$ & 12 & w/food and $\geq 8 \mathrm{oz}$ of water \\
\hline OBD-631 & $\begin{array}{l}\text { Double-blind } \\
\text { Randomized }\end{array}$ & $\begin{array}{l}\text { Placebo ( } 217) \\
\text { LUB } 24 \text { mcg BID (222) }\end{array}$ & 12 & w/food and $\geq 8$ oz of water \\
\hline OBD-632 & $\begin{array}{l}\text { Double-blind } \\
\text { Randomized }\end{array}$ & $\begin{array}{l}\text { Placebo (213) } \\
\text { LUB } 24 \text { mcg BID (224) }\end{array}$ & 12 & w/food and $\geq 8$ oz of water \\
\hline OBD-06S1 & Open-label & $\begin{array}{l}\text { LUB } 24 \mathrm{mcg} \text { BID as needed } \\
\text { (439) }\end{array}$ & 36 & w/food \\
\hline$I B S-C$ & & & & \\
\hline SPI/0211SIB-0221 & $\begin{array}{l}\text { Double-blind } \\
\text { Randomized }\end{array}$ & $\begin{array}{l}\text { Placebo (48) } \\
\text { LUB } 8 \text { mcg BID (52) } \\
\text { LUB } 16 \text { mcg BID (49) } \\
\text { LUB } 24 \text { mcg BID (45) }\end{array}$ & 12 & w/food and $\geq 8$ oz of water \\
\hline SPI/0211SIB-0431 & $\begin{array}{l}\text { Double-blind } \\
\text { Randomized }\end{array}$ & $\begin{array}{l}\text { Placebo (193) } \\
\text { LUB } 8 \text { mcg BID ( } 395)\end{array}$ & $\begin{array}{l}12 \text { (double-blind) } \\
4 \text { (randomized }^{\text {withdrawal) }}{ }^{\mathrm{a}}\end{array}$ & $\mathrm{w} /$ food and $\geq 8 \mathrm{oz}$ of water \\
\hline SPI/0211SIB-0432 & $\begin{array}{l}\text { Double-blind } \\
\text { Randomized }\end{array}$ & $\begin{array}{l}\text { Placebo (194) } \\
\text { LUB } 8 \text { mcg BID ( } 385)\end{array}$ & 12 & w/food and $\geq 8 \mathrm{oz}$ of water \\
\hline SPI/0211SIB-05S1 & Open-label & LUB 8 mcg BID (520) & 36 & w/food and $\geq 8$ oz of water \\
\hline
\end{tabular}

$B I D$ twice daily, $C I C$ chronic idiopathic constipation, $I B S-C$ irritable bowel syndrome with constipation, $L U B$ lubiprostone, $O I C$ opioid-induced constipation

* Number of patients treated

a 139/193 placebo/placebo patients, 143/146 lubiprostone/placebo patients, and 146/151 lubiprostone/lubiprostone patients completed the randomized withdrawal phase of this study

continued opioid treatment during the study. Patients had $<3$ SBMs per week and signs and symptoms of constipation during the baseline washout period. Patients with a history of chronic constipation ( $\geq 90$ days) could be included if they experienced an exacerbation in constipation after the initiation of opioid therapy. Patients receiving opioid treatment for cancer-related pain, abdominal pain, or scleroderma, or for the management of drug addiction were excluded. "Study 1" (NCT01298219) in patients with OIC excluded patients who were receiving opioids of the diphenylheptane class (e.g., methadone). Specific inclusion criteria for IBS-C studies were that patients meet Rome II 
Diagnostic Criteria for IBS assessed using the Rome II Modular Questionnaire Criteria for IBS, have abdominal discomfort/pain of at least mild severity, and experience any two of the following: $<3$ SBMs per week $\geq 25 \%$ of the time, $\geq 25 \%$ of SBMs associated with moderate or greater straining, and $\geq 25 \%$ of SBMs associated with hard or very hard stool consistency. For two of the studies, patients with no SBMs during the baseline period did not have to meet the straining or stool consistency criteria. Patients were excluded from the IBS-C studies if they had diarrhea-predominant or alternating IBS, certain gastrointestinal or abdominal surgeries, known or suspected organic disorders of the small or large bowel, mechanical bowel obstruction or pseudo-obstruction, significant unexplained weight loss, unexplained rectal bleeding, and/or a diagnosis of constipation other than IBS.

\section{Assessments}

Adverse events were noted and recorded at each study visit. Nausea was considered a treatment-emergent AE if it occurred after the initiation of treatment in patients without nausea at baseline or if it was present at baseline and subsequently worsened. The incidence, severity (mild, moderate, and severe), and duration of treatment-emergent AEs of nausea were categorized, as well as whether the events of nausea were associated with study discontinuation. The prebaseline nausea profile for patients in each of the three indications was determined by medical history and use of concomitant medications.

\section{Statistical Analysis}

Patients who entered the treatment period of a specific study and received $\geq 1$ dose of study medication were included in the analyzed study population. Data were pooled in two ways: data from RCTs only and "all trials." Only patients who received lubiprostone were included in the "all trials" analyses, because comparisons between placebo and active treatment for "all trials" would be inappropriate due to the substantially shorter exposure to placebo compared with lubiprostone administered in openlabel extension studies. The incidence of nausea was summarized descriptively, and differences between the placebo and lubiprostone groups were determined by the Fisher's exact test for the RCT analyses only. A Cox proportional hazards regression model was used for analysis of incidence rates for the time to the first occurrence of nausea in RCTs for each indication. Categorical variables analyzed for their effects on the Cox proportional hazard ratios included treatment (active vs placebo), age ( $\geq 65$ vs $<65$ years), and sex. Kaplan-Meier analysis was used to evaluate the cumulative occurrence of nausea AEs over time. Conditions that could predispose patients to nausea [18] were coded using standard preferred terms and used to search patient medical history.

\section{Results}

\section{Baseline Characteristics of Patient Populations}

A summary of analyzed populations is listed in Table 2. The RCT CIC study population consisted of 240 patients who received placebo and 239 who received lubiprostone (24 mcg BID); for OIC, 652 and 663 patients, respectively, received those treatments. For IBS-C, the 832 patients in the lubiprostone group received an 8-mcg BID dose and 435 received placebo. The "all trials" populations consisted of 1113 patients with CIC, 889 with OIC, and 1011 with IBS-C. Most patients in each clinical development program were women.

For each indication, the percentages of patients in RCTs reporting nausea at baseline or who had received treatment for nausea before randomization were statistically similar between patients who received placebo and lubiprostone. However, patients with OIC had a higher incidence of pretreatment nausea than those with CIC or IBS-C (Table 2).

\section{Nausea Incidences During Treatment}

The crude incidence of treatment-emergent nausea in the RCT populations was significantly higher in patients who received lubiprostone (24 mcg BID for CIC and OIC; 8 mcg BID for IBS-C) compared with placebo for each indication (CIC, 29.3 vs $6.3 \%$, respectively; OIC, 13.4 vs $6.4 \%$; IBS-C, 10.9 vs $6.4 \%$; Table 2 ). The crude incidences of nausea in the RCT and "all trials" lubiprostone-treated patients were similar within each indication (Table 2).

For CIC analysis, the percentages of patients in RCTs reporting mild, moderate, and severe nausea were significantly higher with lubiprostone ( $24 \mathrm{mcg}$ BID) than placebo (19.2 vs $3.3 \%, 7.9$ vs $2.9 \%$, and 2.1 vs $0 \%$, respectively; Table 2). For the OIC analysis, the percentages of patients in RCTs reporting mild ( 8.0 vs $3.7 \%$ ) and moderate (4.4 vs $1.7 \%$ ), but not severe (1.1 vs $1.1 \%$ ) nausea, were significantly higher for lubiprostone (24 mcg BID) compared with placebo. For IBS-C analysis, the percentage of patients in RCTs reporting moderate nausea was significantly higher with lubiprostone $(8 \mathrm{mcg}$ BID) than placebo (4.0 vs $1.4 \%$ ), but the percentages of patients reporting mild or severe nausea were similar (6.4 vs $4.8 \%$ and 0.6 vs $0.2 \%$, respectively). In the "all trials" CIC population, who were treated with lubiprostone for longer periods, incidences of moderate and severe nausea were slightly higher 
Table 2 Patient background and summary of nausea incidence by indication

\begin{tabular}{|c|c|c|c|c|c|c|}
\hline & \multicolumn{2}{|l|}{$\mathrm{CIC}$} & \multicolumn{2}{|l|}{ OIC } & \multicolumn{2}{|l|}{ IBS-C } \\
\hline & $\begin{array}{l}\text { Placebo } \\
n=240\end{array}$ & $\begin{array}{l}\text { Lubiprostone } \\
24 \text { mcg BID } \\
n=239\end{array}$ & $\begin{array}{l}\text { Placebo } \\
n=652\end{array}$ & $\begin{array}{l}\text { Lubiprostone } \\
24 \text { mcg BID } \\
n=663\end{array}$ & $\begin{array}{l}\text { Placebo } \\
n=435\end{array}$ & $\begin{array}{l}\text { Lubiprostone } \\
8 \text { mcg BID } \\
n=832\end{array}$ \\
\hline \multicolumn{7}{|l|}{ Randomized controlled trials } \\
\hline \multicolumn{7}{|l|}{ Sex, $n(\%)$} \\
\hline Male & $25(10.4)$ & $28(11.7)$ & $244(37.4)$ & $247(37.3)$ & $31(7.1)$ & $75(9.0)$ \\
\hline Female & $215(89.6)$ & $211(88.3)$ & $408(62.6)$ & $416(62.7)$ & $404(92.9)$ & $757(91.0)$ \\
\hline $\begin{array}{l}\text { Exposure to lubiprostone, } \\
\text { median (range), mcg/day }\end{array}$ & 0 & $46.3(18.0-51.4)$ & 0 & $43.3(2.0-129.6)$ & 0 & $14.18(0-50.5)$ \\
\hline \multicolumn{7}{|l|}{ Pretreatment nausea, $n(\%)$} \\
\hline Medical history of nausea & $8(3.3)$ & $10(4.2)$ & $60(9.2)$ & $56(8.4)$ & $8(1.8)$ & $26(3.1)$ \\
\hline Prior treatment for nausea & $1(0.4)$ & $1(0.4)$ & $16(2.5)$ & $21(3.2)$ & $3(0.7)$ & $7(0.8)$ \\
\hline \multicolumn{7}{|l|}{ Treatment-emergent nausea, $n(\%)$} \\
\hline Crude incidence & $15(6.3)$ & $70(29.3)^{*}$ & $42(6.4)$ & $89(13.4)^{*}$ & $28(6.4)$ & $91(10.9)^{\dagger}$ \\
\hline Mild $^{\mathrm{a}}$ & $8(3.3)$ & $46(19.2)^{*}$ & $24(3.7)$ & $53(8.0)^{*}$ & $21(4.8)$ & $53(6.4)$ \\
\hline Moderate $^{\mathrm{a}}$ & $7(2.9)$ & $19(7.9)^{\S}$ & $11(1.7)$ & $29(4.4)^{\dagger}$ & $6(1.4)$ & $33(4.0)^{\S}$ \\
\hline Severe $^{a}$ & 0 & $5(2.1)^{\S}$ & $7(1.1)$ & $7(1.1)$ & $1(0.2)$ & $5(0.6)$ \\
\hline \multirow[t]{2}{*}{ Leading to discontinuation } & 0 & $12(5.0)^{*}$ & 0 & $17(2.6)^{*}$ & $3(0.7)$ & $10(1.2)$ \\
\hline & \multicolumn{2}{|c|}{$\begin{array}{l}\text { CIC } \\
\text { Lubiprostone } 24 \mathrm{mcg} \text { BID } \\
n=1113\end{array}$} & \multicolumn{2}{|c|}{$\begin{array}{l}\text { OIC } \\
\text { Lubiprostone } 24 \text { mcg BID } \\
n=889\end{array}$} & \multicolumn{2}{|c|}{$\begin{array}{l}\text { IBS-C } \\
\text { Lubiprostone } 8 \text { mcg BID } \\
n=1011\end{array}$} \\
\hline \multicolumn{7}{|l|}{ All trials } \\
\hline \multicolumn{7}{|l|}{ Sex, $n(\%)$} \\
\hline Male & \multicolumn{2}{|c|}{$146(13.1)$} & \multicolumn{2}{|c|}{$333(37.5)$} & \multicolumn{2}{|c|}{$89(8.8)$} \\
\hline Female & \multicolumn{2}{|c|}{$967(86.9)$} & \multicolumn{2}{|c|}{$556(62.5)$} & \multicolumn{2}{|c|}{$922(91.2)$} \\
\hline $\begin{array}{l}\text { Exposure to lubiprostone, median } \\
\text { (range), } \mathrm{mcg} / \text { day }\end{array}$ & \multicolumn{2}{|c|}{$43.4(0.8-204.0)$} & \multicolumn{2}{|c|}{$40.8(2.0-129.6)$} & \multicolumn{2}{|c|}{$14.8(0-50.5)$} \\
\hline \multicolumn{7}{|l|}{ Pretreatment nausea, $n(\%)$} \\
\hline Medical history of nausea & \multicolumn{2}{|c|}{$23(2.1)$} & \multicolumn{2}{|c|}{$81(9.1)$} & \multicolumn{2}{|c|}{$26(2.6)$} \\
\hline Prior treatment for nausea & \multicolumn{2}{|c|}{$7(0.6)$} & \multicolumn{2}{|c|}{$22(2.5)$} & \multicolumn{2}{|c|}{$7(0.7)$} \\
\hline \multicolumn{7}{|l|}{ Treatment-emergent nausea, $n(\%)$} \\
\hline Crude incidence & & $(31.1)$ & 12 & 3.9) & 115 & \\
\hline Mild $^{\mathrm{a}}$ & & $(16.5)$ & & & 63 & \\
\hline Moderate $^{\mathrm{a}}$ & & $(11.1)$ & & & 43 & \\
\hline Severe ${ }^{a}$ & & $(3.5)$ & & & & \\
\hline Leading to discontinuation & & $(8.7)$ & & & 13 & \\
\hline
\end{tabular}

$B I D$ twice daily, $C I C$ chronic idiopathic constipation, IBS-C irritable bowel syndrome with constipation, OIC opioid-induced constipation

$* P<0.001$, Fisher's exact test

${ }^{\dagger} P<0.01$, Fisher's exact test

$\S P<0.05$, Fisher's exact test

${ }^{a}$ Maximum reported severity for each patient

than observed for RCTs. Similar incidences of mild, moderate, and severe nausea were observed in the lubiprostone-treated "all trials" OIC population compared with the RCT population. The lubiprostone-treated "all trials" IBS-C population reported similar nausea rates by severity compared with the RCT population.

The percentage of patients discontinuing treatment owing to nausea in RCTs was low but significantly greater 
in patients who received lubiprostone $24 \mathrm{mcg}$ BID compared with placebo in the CIC and OIC studies. On the other hand, patients who received lubiprostone $8 \mathrm{mcg}$ BID had similar rates of discontinuation to placebo (Table 2). In the CIC and IBS-C studies, no AEs of nausea met the criteria to be considered as serious events (e.g., hospitalization). In the OIC studies, one patient treated with lubiprostone experienced a serious $\mathrm{AE}$ of nausea; however, this event was considered unrelated to study medication by the study investigator.

In patients who reported severe nausea, $40-80 \%$ of patients in each group had a history of medical conditions predisposing them to nausea, though few had a medical history of preexisting nausea (Table 3). Discontinuations due to severe nausea were more common in the longer "all trials" analysis of lubiprostone than in the shorter RCTs.

\section{Patients Reporting a Single Nausea Event or Persistent Nausea}

Among lubiprostone-treated patients in the "all trials" populations who reported any AE of nausea (CIC [24 mcg BID], $n=346$; OIC [24 mcg BID], $n=124$; IBS-C [(8 mcg BID], $n=115), 83.5-88.7 \%$ reported only one nausea event (Fig. 1a-c). More than 70\% (70.7-73.8\%) of patients reporting a single event of nausea who did not have a dose adjustment completed the full treatment period. Across the three indications, $8.3-17.7 \%$ of patients who reported a single nausea event required lubiprostone dose reduction to once daily or a temporary interruption of lubiprostone treatment, which allowed the majority of these patients to complete the full treatment period. Among patients who reported $\geq 1$ event of nausea (CIC, $n=69$; OIC, $n=18$; IBS-C, $n=10$ ), $55 \%$ with CIC, $78 \%$ with OIC, and $100 \%$ with IBS-C remained in the study.

\section{Temporal Pattern of Nausea}

In the "all trials" population, $64.3 \%$ of overall nausea events $(393 / 611)$ occurred during the first 5 days of treatment with lubiprostone (CIC, 77.2\% [267/346]; OIC, $45.2 \%$ [56/124]; IBS-C, 49.6\% [70/141]). In RCTs, the median (range) for the first report of nausea was 2 (1-27), 5 (1-84), and 3 (1-90) days for the CIC, OIC, and IBS-C studies, respectively (Fig. 2). Median values for the first report of nausea in the long-term extension studies ranged from 2 to 8.5 days.

Table 3 Medical history of nausea, history of medical conditions predisposing to nausea, and discontinuations due to nausea in patients who reported severe nausea

\begin{tabular}{|c|c|c|c|c|c|c|}
\hline \multirow[t]{2}{*}{ Patients, $n$} & \multicolumn{2}{|l|}{$\mathrm{CIC}$} & \multicolumn{2}{|l|}{ OIC } & \multicolumn{2}{|l|}{ IBS-C } \\
\hline & $\begin{array}{l}\text { Placebo } \\
n=0\end{array}$ & $\begin{array}{l}\text { Lubiprostone } 24 \mathrm{mcg} \\
\text { BID } \\
n=5\end{array}$ & $\begin{array}{l}\text { Placebo } \\
n=7\end{array}$ & $\begin{array}{l}\text { Lubiprostone } 24 \mathrm{mcg} \\
\text { BID } \\
n=7\end{array}$ & $\begin{array}{l}\text { Placebo } \\
n=1\end{array}$ & $\begin{array}{l}\text { Lubiprostone } 8 \mathrm{mcg} \\
\text { BID } \\
n=5\end{array}$ \\
\hline \multicolumn{7}{|l|}{ Randomized controlled trials } \\
\hline Medical history of nausea & NA & 0 & 3 & 1 & 0 & 1 \\
\hline $\begin{array}{l}\text { History of predisposing } \\
\text { conditions }^{\mathrm{a}}\end{array}$ & NA & 2 & 5 & 5 & 0 & 4 \\
\hline \multirow[t]{2}{*}{ Discontinuation due to nausea } & NA & 1 & 0 & 2 & 1 & 1 \\
\hline & & \multicolumn{2}{|l|}{$\begin{array}{l}\text { CIC } \\
\text { Lubiprostone } 24 \text { mcg BID } \\
n=39\end{array}$} & $\begin{array}{l}\text { OIC } \\
\text { Lubiprostone } 24 \mathrm{mcg} \text { BID } \\
n=9\end{array}$ & & $\begin{array}{l}\text { IBS-C } \\
\text { Lubiprostone } 8 \mathrm{mcg} \text { BID } \\
n=9\end{array}$ \\
\hline \multicolumn{7}{|l|}{ All trials } \\
\hline \multicolumn{2}{|l|}{ Medical history of nausea } & \multicolumn{2}{|l|}{2} & \multicolumn{2}{|l|}{1} & 1 \\
\hline \multicolumn{2}{|l|}{ History of predisposing conditions ${ }^{\mathrm{a}}$} & 21 & & \multicolumn{2}{|l|}{7} & 6 \\
\hline \multicolumn{2}{|l|}{ Discontinuation due to nausea } & 20 & & \multicolumn{2}{|l|}{2} & 1 \\
\hline \multicolumn{7}{|c|}{$\begin{array}{l}B I D \text { twice daily, } C I C \text { chronic idiopathic constipation, } I B S-C \text { irritable bowel syndrome with constipation, } N A \text { not applicable, } O I C \text { opioid-induced } \\
\text { constipation }\end{array}$} \\
\hline \multicolumn{7}{|c|}{$\begin{array}{l}\text { a The following preferred terms were used: alcoholism, anaphylactic reaction, anorexia nervosa, appendicitis, vertigo positional, bulimia } \\
\text { nervosa, chemotherapy, cholecystitis, concussion, Crohn's disease, cyclic vomiting syndrome, depression, diabetic ketoacidosis, dizziness, otitis } \\
\text { media, food poisoning, gastroesophageal reflux disease, impaired gastric emptying, general anesthesia, generalized anxiety disorder, myocardial } \\
\text { infarction, cardiac failure, hepatitis, pyrexia, hydrocephalus, hyperparathyroidism, hyperthyroidism, hypoparathyroidism, intestinal ischemia, } \\
\text { intestinal obstruction, intracranial hematoma, intussusception, irritable bowel syndrome, hepatic cancer, hepatic failure, Meniere's disease, } \\
\text { meningitis, migraine, milk allergy, vomiting in pregnancy, pancreatic carcinoma, pancreatitis, peptic ulcer, benign intracranial hypertension, } \\
\text { pyloric stenosis, radiotherapy, rotavirus infection, pain, craniocerebral injury, vestibular neuronitis, or gastroenteritis viral }\end{array}$} \\
\hline
\end{tabular}



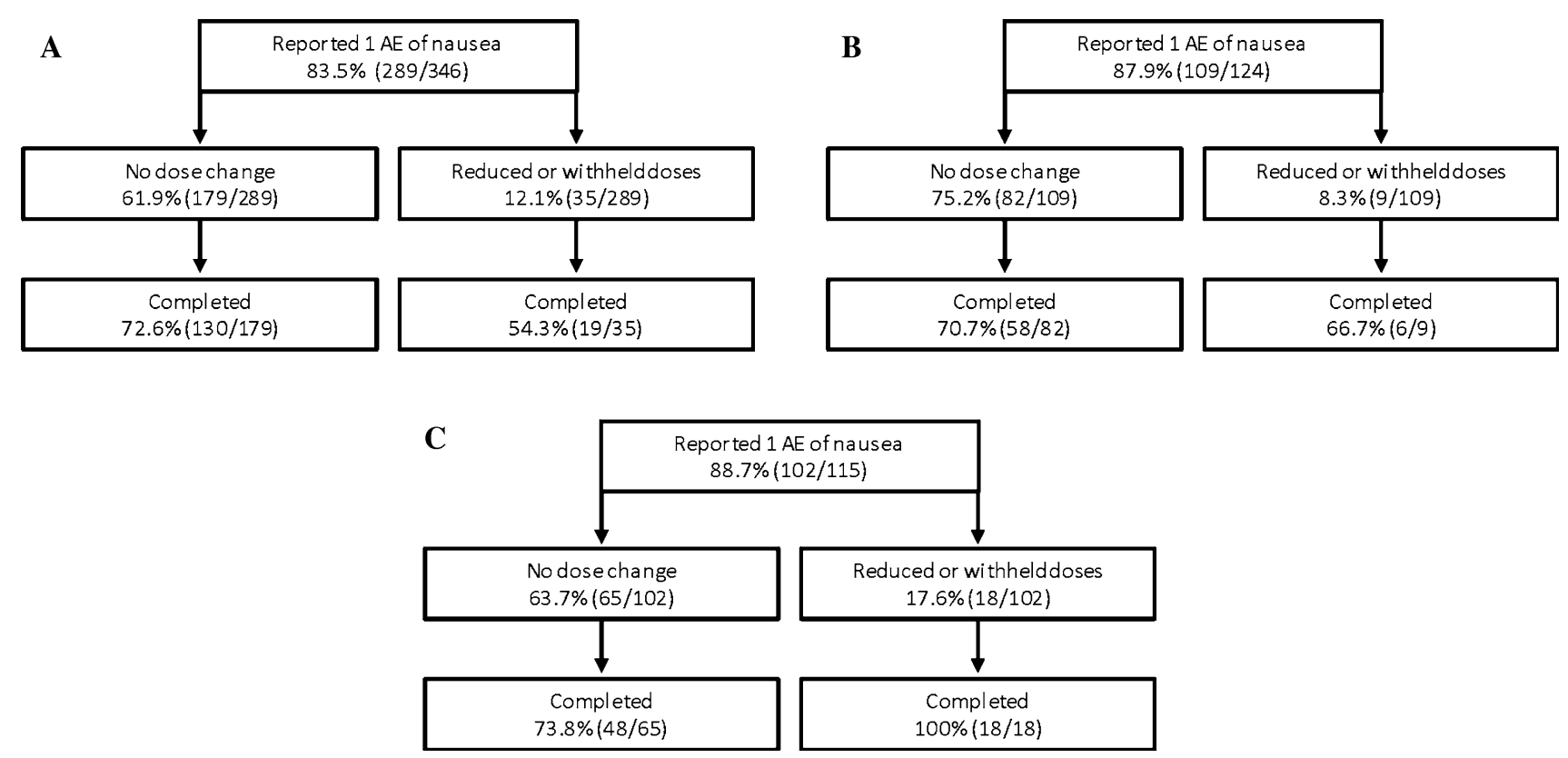

Fig. 1 Treatment continuation among lubiprostone-treated patients who reported only one AE of nausea in the a chronic idiopathic constipation, b opioid-induced constipation, and $\mathbf{c}$ irritable bowel syndrome with constipation studies. $A E$ adverse event

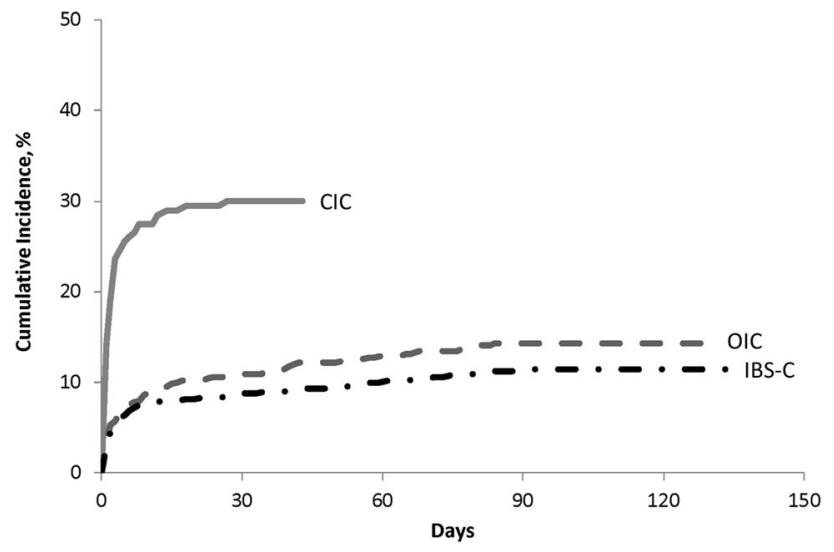

Fig. 2 Cumulative incidence of events of nausea in lubiprostonetreated patients in randomized controlled trials. The solid line denotes CIC, the dashed line denotes OIC, and the dash-dotted line denotes IBS-C. $C I C$ chronic idiopathic constipation, IBS-C irritable bowel syndrome with constipation, $O I C$ opioid-induced constipation

\section{Sex, Age, and Body Mass Index as Predictors of Nausea}

In the CIC, OIC, and IBS-C RCTs, comparisons between patients who received lubiprostone or placebo found that nausea rates were not significantly different between women or men, or for those aged $<65$ or $\geq 65$ years of age or with body mass index (BMI) $<25$ or $\geq 25$ (all $P$ values $>0.394$; Table 4). Rates of severe nausea were low overall. Rates of nausea by sex, age, and BMI were also analyzed within the group of patients in RCTs who received lubiprostone treatment. In patients with CIC who received lubiprostone, a significantly higher rate of nausea was observed in women compared with men $(P=0.007)$, and in patients aged $<65$ versus $\geq 65$ years of age $(P=0.028)$ (Table 4). There were no significant differences in the rates of severe nausea in any of these subgroups. In patients with OIC who received lubiprostone, there were no significant differences in the rates of nausea by sex, age group, or BMI, although there was a significantly higher rate $(P=0.050)$ of severe nausea in women compared with men (Table 4). In patients with IBS-C who received lubiprostone, the rates of nausea $(P=0.0140)$ and severe nausea $(P=0.0160)$ were significantly higher in patients with BMI $<25$ compared with those with $\mathrm{BMI} \geq 25$ (Table 4).

\section{Discussion}

The pooled ("all trials") analyses indicated that most patients experienced no nausea during treatment with lubiprostone. When nausea did occur, it was usually a single event, and the typical onset was within the first 5 days of treatment. The majority of nausea AEs were mild or moderate in severity and did not result in discontinuation of treatment. Although the rates of severe nausea were low, a higher rate of severe nausea was observed in patients with IBS-C with a BMI $<25$ and in women with OIC. Furthermore, nausea may be more common in women 
Table 4 Nausea incidence by sex, age group, and body mass index

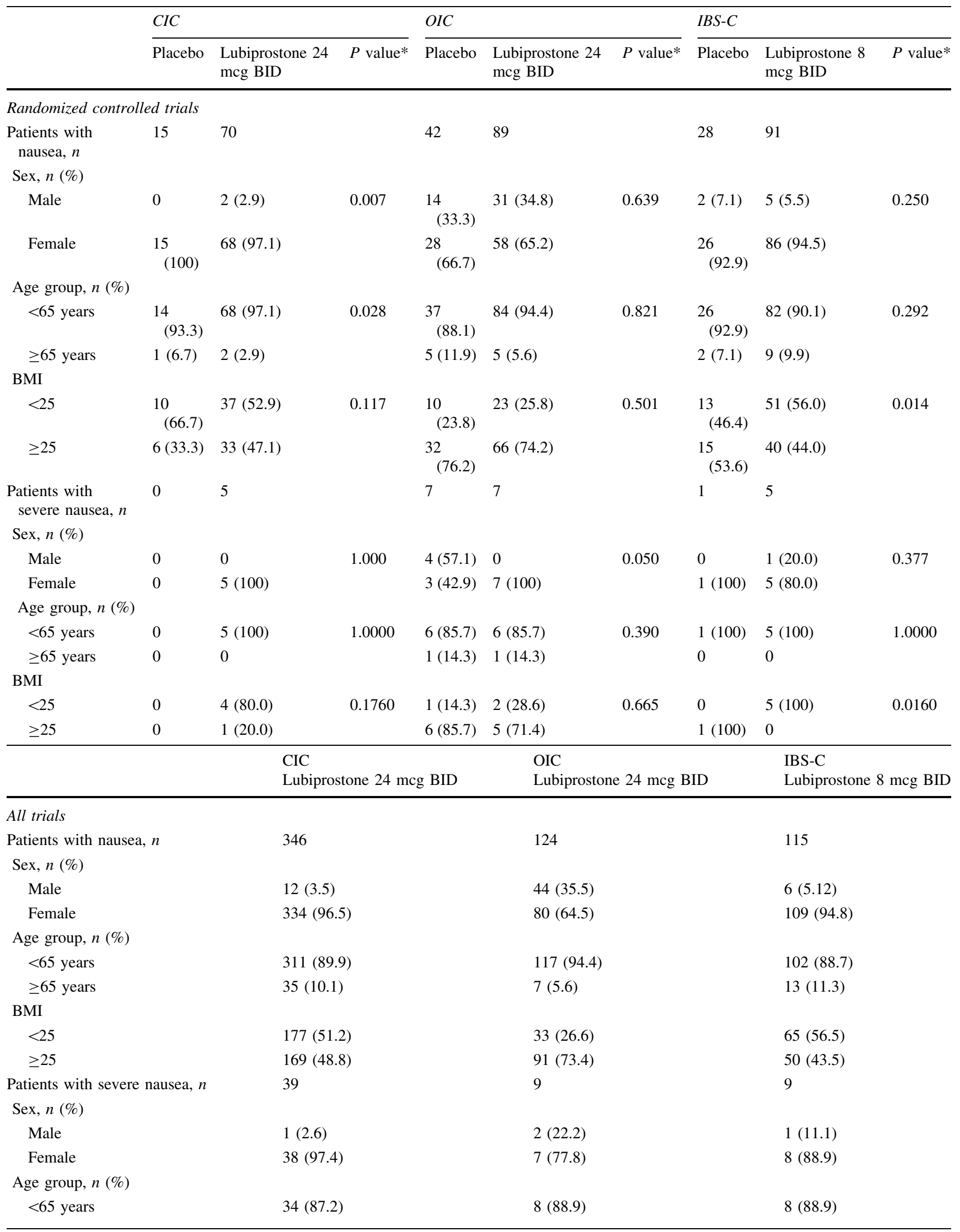


Table 4 continued

\begin{tabular}{llll}
\hline & $\begin{array}{l}\text { CIC } \\
\text { Lubiprostone 24 mcg BID }\end{array}$ & $\begin{array}{l}\text { OIC } \\
\text { Lubiprostone 24 mcg BID }\end{array}$ & $\begin{array}{l}\text { IBS-C } \\
\text { Lubiprostone 8 mcg BID }\end{array}$ \\
\hline $\begin{array}{l}265 \text { years } \\
\text { BMI, } n(\%)\end{array}$ & $5(12.8)$ & $1(11.1)$ & $1(11.1)$ \\
$<25$ & & $2(22.2)$ & $7(77.8)$ \\
$\geq 25$ & $23(59.0)$ & $7(77.8)$ & $2(22.2)$
\end{tabular}

$B I D$ twice daily, $B M I$ body mass index, $C I C$ chronic idiopathic constipation, $I B S$ - $C$ irritable bowel syndrome with constipation, $O I C$ opioidinduced constipation

* $P$ values for comparison of the differences of the incidence rate between the subgroups in patients treated with lubiprostone using the Fisher's exact test

compared with men as well as in younger versus older adults at the higher dose (24 mcg BID).

Our data cannot definitively support or refute a doseresponse relationship with the incidence of treatmentemergent nausea associated with lubiprostone. The higher incidence of nausea with lubiprostone in patients with CIC, compared with patients with IBS-C, would seem consistent with the threefold difference in dose ( 24 vs 8 mcg BID, respectively).The incidence of nausea in patients with OIC who received lubiprostone $24 \mathrm{mcg}$ BID was lower than the incidence in patients with CIC at the same dose and closer to the incidence in patients with IBS-C, who received the lower dose. Arguably, the CIC and IBS-C patient populations have more overlap in terms of the clinical characteristics and pathophysiology than does the OIC patient population where the pathogenesis of constipation is more clearly defined. No dose-dependent relationship between lubiprostone dose and nausea was observed in a doubleblind, 3-week study with placebo or lubiprostone at total doses of 24, 48, and $72 \mathrm{mcg} /$ day in patients with CIC [5].

The percentage of lubiprostone-treated patients reporting nausea was higher in the CIC study population than in the other two study populations. Comparing nausea rates across the different indications may not be warranted because of differences in patient characteristics, particularly when considering patients with OIC versus those with CIC or IBS-C. For example, the prevalence of baseline (pretreatment) nausea was considerably greater in patients with OIC compared with patients with CIC and IBS-C. It is also possible that patients with OIC may have been less sensitive to the occurrence of nausea caused by lubiprostone because the use of opioid agonists [19] is itself often associated with nausea.

While this study did not explore the relationship between efficacy of lubiprostone and adverse effects, independent pooled analyses of randomized controlled trials have been conducted for CIC, OIC, and IBS-C [20-22]. These pooled analyses supported the beneficial effects of lubiprostone across efficacy endpoints assessed. Further, in each of these pooled analyses, the percentage of patients discontinuing treatment due to lack of efficacy was lower than that due to AEs. Importantly, nausea was not responsible for a large number of discontinuations, and the rates of nausea tended to decrease over the course of the study.

The higher prevalence of nausea in young women treated with lubiprostone in RCTs is consistent with observations across studies that show greater incidences of constipation and gastrointestinal dyspeptic symptoms, including delayed gastric emptying, as well as slowed colon transit time, in females than in males [23-28]. Similarly, a higher incidence of constipation and dyspeptic symptoms has been reported in younger versus elderly adults as well as in women of childbearing potential [23-25, 28, 29]. Given the reported effects of lubiprostone on delaying gastric emptying time [3], it is possible that this effect is exacerbated in women who already have elevated constipation and gastrointestinal dyspeptic symptoms at baseline and may contribute to the increased rates of nausea observed in younger females.

While this study focused on the incidence of nausea in constipated patients, nausea rates were evaluated independently of the other AEs associated with lubiprostone treatment. In particular, dyspnea has been reported in 2.5 and $1.3 \%$ of lubiprostone-treated CIC and OIC patients, respectively [30]. In clinical studies, several patients discontinued lubiprostone treatment because of AEs regardless of severity, and in several patients continuing treatment, a recurrence of symptoms was observed [30]. Further, in the CIC and IBS-C trials, headache was among the most common treatment-related AEs $(\geq 5 \%)$ leading to study discontinuation [5-7]. Collectively, these findings suggest that individual sensitivities of patients to lubiprostone and the potential interactions between AEs may have had a substantial effect on the observed safety profile.

The mechanisms underlying lubiprostone-induced nausea have not been identified. In addition to activation of ClC-2 chloride channels and the resultant increase in intestinal secretion, lubiprostone has other effects on gastrointestinal function [2]. In two studies conducted in 
healthy adults, lubiprostone significantly delayed gastric emptying and increased fasting gastric volume [3, 31]. These findings differ from what has been observed in preclinical studies, which show accelerated gastric emptying with lubiprostone treatment [32]. However, accelerated gastric emptying was not observed at lower doses, which are more comparable to those administered in the clinical setting.

While delayed gastric emptying and increased fasting gastric volume may play a role in mediating lubiprostoneinduced nausea, other factors such as increased intestinal secretion and suppression of defecation may contribute to this phenomenon. In patients with functional dyspepsia, small intestinal distension has been associated with the occurrence of nausea, suggesting that increased secretion in the small intestine resulting in local distension may contribute to nausea symptoms [33]. Further, it is well known that suppression of defecation increases gastric emptying time, which could induce nausea, as has been observed in studies with healthy volunteers [34]. Therefore, patients with defecation disorders might be more prone to experiencing nausea while taking lubiprostone.

In addition to perturbations in intestinal physiology and defecation, the time of drug intake relative to food consumption may also modify the side-effect profile of lubiprostone. In the first CIC study (RTU0211SC9921), lubiprostone was taken before a meal (Table 1), whereas in all other studies, it was taken during a meal. Consistent with the observation that less nausea has been observed when lubiprostone is co-administered with food, the aforementioned study conducted in healthy adults found that increases in gastric volume did not occur when lubiprostone was administered after a fully satiating meal [3]. This observation is consistent with the US Food and Drug Administration's recommendation to take the medication with food and water [1].

One possible explanation for why patients with CIC exhibited the highest incidence of nausea in the clinical trials is that, unlike patients in the OIC and IBS-C studies, no explicit instruction was given to take the treatment with food. Since a detailed characterization of nausea was not a specific objective of the pivotal studies, only limited data on nausea were collected, thus limiting the scope of the current analyses.

In conclusion, nausea was more common in patients with CIC compared with OIC and IBS-C. In patients with CIC, but not OIC or IBS-C, women were more likely than men to report nausea. Most patients treated with lubiprostone in the pooled study analyses for CIC, OIC, and IBS-C who reported nausea reported only a single incidence, and most of those events were of mild to moderate severity. In general, patients who experienced nausea were able to complete the studies. Useful strategies for the management of lubiprostone-induced nausea include emphasizing that the medication should be taken with food and water (the recommended dosing procedure), reducing the dose, or temporarily withholding doses [1]. Treating physicians may wish to be particularly vigilant by expectantly advising women (CIC and OIC), patients aged $<65$ (CIC), and patients with a BMI $<25$ (IBS-C) for the potential of nausea. Such an approach may be beneficial in helping patients achieve successful therapy.

Acknowledgments Writing and editorial support was provided by Patrick Little, PhD, and Michael Theisen, PhD, of Complete Publication Solutions, LLC (North Wales, PA, USA), and was funded by Takeda Pharmaceuticals International.

Funding These analyses were funded by Sucampo Pharma Americas, LLC (Bethesda, MD), and Takeda Pharmaceuticals International (Deerfield, IL).

\section{Compliance with ethical standards}

Conflicts of interest Dr Cryer has consulting relationships with Pfizer, Ritter Pharmaceuticals, PLx Pharma, Iroko Pharmaceuticals, and Sucampo Pharmaceuticals, Inc. Dr Chey has served as a consultant for Actavis, Ardelyx, AstraZeneca, IM Health, Ironwood Pharmaceuticals, Nestlé, Prometheus Laboratories, QOL, SK, Sucampo Pharmaceuticals, Inc., and Takeda Pharmaceuticals, Inc. He has received research grants from IM Health, Ironwood Pharmaceuticals, Nestlé, Prometheus Laboratories, and Vibrant; he is the cochief marketing officer for My Total Health. Drs Drossman and Webster have no conflicts of interest to disclose. Dr Habibi and Mr. Wang are employees of Sucampo Pharma Americas, LLC, and stock shareholders of Sucampo Pharmaceuticals, Inc.

Human and animal rights For this type of study, formal consent is not required.

Open Access This article is distributed under the terms of the Creative Commons Attribution-NonCommercial 4.0 International License (http://creativecommons.org/licenses/by-nc/4.0/), which permits any noncommercial use, distribution, and reproduction in any medium, provided you give appropriate credit to the original author(s) and the source, provide a link to the Creative Commons license, and indicate if changes were made.

\section{References}

1. Amitiza (lubiprostone) [package insert]. Deerfield, IL: Takeda Pharmaceuticals; 2016.

2. Lacy B, Levy L. Lubiprostone: a chloride channel activator. $J$ Clin Gastroenterol. 2007;41:345-351.

3. Camilleri M, Bharucha A, Ueno R, et al. Effect of a selective chloride channel activator, lubiprostone, on gastrointestinal transit, gastric sensory, and motor functions in healthy volunteers. Am J Physiol Gastrointest Liver Physiol. 2006;290:G942-G947.

4. Fukudo S, Hongo M, Kaneko H, Takano M, Ueno R. Lubiprostone increases spontaneous bowel movement frequency and quality of life in patients with chronic idiopathic constipation. Clin Gastroenterol Hepatol. 2015;13:294.e295-301.e295.

5. Johanson J, Ueno R. Lubiprostone, a locally acting chloride channel activator, in adult patients with chronic constipation: a 
double-blind, placebo-controlled, dose-ranging study to evaluate efficacy and safety. Aliment Pharmacol Ther. 2007;25:1351-1361.

6. Lembo A, Johanson J, Parkman H, Rao S, Miner PJ, Ueno R. Long-term safety and effectiveness of lubiprostone, a chloride channel (ClC-2) activator, in patients with chronic idiopathic constipation. Dig Dis Sci. 2011;56:2639-2645.

7. Johanson J, Morton D, Geenen J, Ueno R. Multicenter, 4-week, double-blind, randomized, placebo-controlled trial of lubiprostone, a locally-acting type-2 chloride channel activator, in patients with chronic constipation. Am $J$ Gastroenterol. 2008;103:170-177.

8. Barish C, Drossman D, Johanson J, Ueno R. Efficacy and safety of lubiprostone in patients with chronic constipation. Dig Dis Sci. 2010;55:1090-1097.

9. Johanson JF, Gargano MA, Holland PC, Patchen ML, Ueno R. Phase III patient assessments of the effects of lubiprostone, a chloride channel-2 (ClC-2) activator, for the treatment of constipation. Am J Gastroenterol. 2005;100:S329-S330.

10. Ueno R, Wahle A, Panas R, Joswick TR, Rivera E. Evaluation of safety and efficacy in a twelve-month study of lubiprostone for the treatment of chronic idiopathic constipation. Am J Gastroenterol. 2006;101:S491.

11. Jamal MM, Adams AB, Jansen JP, Webster LR. A randomized, placebo-controlled trial of lubiprostone for opioid-induced constipation in chronic non-cancer pain. Am $J$ Gastroenterol. 2015;110:725-732.

12. Cryer B, Katz S, Vallejo R, Popescu A, Ueno R. A randomized study of lubiprostone for opioid-induced constipation in patients with chronic noncancer pain. Pain Med. 2014;15:1825-1834.

13. Drossman DA, Chey WD, Johanson JF, et al. Clinical trial: lubiprostone in patients with constipation-associated irritable bowel syndrome-results of two randomized, placebo-controlled studies. Aliment Pharmacol Ther. 2009;29:329-341.

14. Johanson JF, Drossman DA, Panas R, Wahle A, Ueno R. Clinical trial: phase 2 study of lubiprostone for irritable bowel syndrome with constipation. Aliment Pharmacol Ther. 2008;27:685-696.

15. Chey W, Drossman D, Johanson J, Scott C, Panas R, Ueno R. Safety and patient outcomes with lubiprostone for up to 52 weeks in patients with irritable bowel syndrome with constipation. Aliment Pharmacol Ther. 2012;35:587-599.

16. Spierings E, Joswick T, Lindner E, Woldegeorgis F, Ueno R. Long-term safety and efficacy of lubiprostone in opioid-induced bowel dysfunction in patients with chronic, non-cancer pain: Results of a phase 3, open-label clinical trial. Paper presented at American College of Gastroenterology Annual Scientific Meeting; October 19-24, 2012; Las Vegas, Nevada.

17. Halpern SH, Douglas MJ. Appendix- Jadad scale for reporting randomized controlled trials. In: Halpern SH, Douglas MJ, eds. Evidence-based Obstetric Anesthesia. Oxford, UK: Blackwell Publishing Ltd; 2005:237-238.

18. Mayo Clinic. Nausea and vomiting causes: symptoms. http:// www.mayoclinic.org/symptoms/nausea/basics/causes/sym20050736. Accessed February 25, 2015.

19. Labianca R, Sarzi-Puttini P, Zuccaro SM, Cherubino P, Vellucci R, Fornasari D. Adverse effects associated with non-opioid and opioid treatment in patients with chronic pain. Clin Drug Investig. 2012;32:53-63.

20. Mareya SM, Wang M, Losch-Beridon T, Lichtlen P. Su1586 lubiprostone responder rates in patients with chronic idiopathic constipation: increased frequency of spontaneous bowel movements and improved constipation-related symptoms. Gastroenterol. 2016;150:S534-S535.

21. Losch-Beridon T, Mareya S, Wang M, Lichtlen P. Su1585 lubiprostone responder rates in patients with opioid-induced constipation: increased frequency of complete spontaneous bowel movements. Gastroenterol. 2016;150:S534.

22. Chang L, Chey W, Drossman D, et al. Mo1262 effects of baseline abdominal pain on response to lubiprostone in patients with constipation-predominant irritable bowel syndrome. Gastroenterol. 2015;148:S-653.

23. Choung RS, Locke GR 3rd, Schleck CD, Zinsmeister AR, Talley NJ. Cumulative incidence of chronic constipation: a populationbased study 1988-2003. Aliment Pharmacol Ther. 2007;26:1521-1528.

24. Kepenekci I, Keskinkilic B, Akinsu F, et al. Prevalence of pelvic floor disorders in the female population and the impact of age, mode of delivery, and parity. Dis Colon Rectum. 2011;54:85-94.

25. Kurniawan I, Simadibrata M. Management of chronic constipation in the elderly. Acta Med Indones. 2011;43:195-205.

26. McCrea GL, Miaskowski C, Stotts NA, Macera L, Varma MG. A review of the literature on gender and age differences in the prevalence and characteristics of constipation in North America. J Pain Symptom Manage. 2009;37:737-745.

27. Pare P, Ferrazzi S, Thompson WG, Irvine EJ, Rance L. An epidemiological survey of constipation in canada: definitions, rates, demographics, and predictors of health care seeking. Am J Gastroenterol. 2001;96:3130-3137.

28. Preston DM, Lennard-Jones JE. Severe chronic constipation of young women: 'idiopathic slow transit constipation'. Gut. 1986;27:41-48.

29. Gallegos-Orozco JF, Foxx-Orenstein AE, Sterler SM, Stoa JM. Chronic constipation in the elderly. Am $J$ Gastroenterol. 2012;107:18-25.

30. Chamberlain S, Rao S. Safety evaluation of lubiprostone in the treatment of constipation and irritable bowel syndrome. Expert Opin Drug Saf. 2012;11:841-850.

31. Hooks S, Rutland T, Di Palma J. Lubiprostone neither decreases gastric and small-bowel transit time nor improves visualization of small bowel for capsule endoscopy: a double-blind, placebocontrolled study. Gastrointest Endosc. 2009;70:942-946.

32. Song J, Yin J, Xu X, Chen J. Prokinetic effects of large-dose lubiprostone on gastrointestinal transit in dogs and its mechanisms. Am J Transl Res. 2015;7:513-521.

33. Barbera R, Feinle C, Read NW. Abnormal sensitivity to duodenal lipid infusion in patients with functional dyspepsia. Eur J Gastroenterol Hepatol. 1995; 7:1051-1057.

34. Tjeerdsma H, Smout A, Akkermans L. Voluntary suppression of defecation delays gastric emptying. Dig Dis Sci. 1993;38:832-836. 